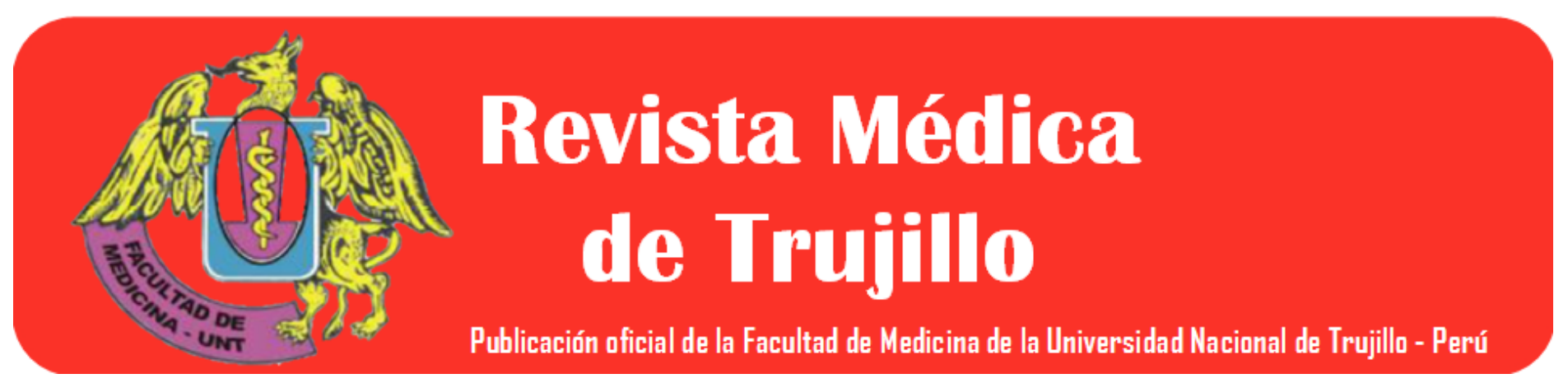

\title{
Editorial
}

\section{COVID-19 y obesidad}

\author{
COVID-19 and obesity
}

Juan Jorge Huamán-Saavedra

La COVID-19 sigue aumentando en número de casos en el mundo. En la fecha 9 de diciembre alcanza el total de 268.208.096 infectados habiendo causado 5.284.641 muertes $^{1}$. Se han vacunado a 8.321.186.484 personas, que aunque no impide la infección, disminuye significativamente su severidad, la hospitalización y la mortalidad. Siguen en vigencia, junto a la vacunación, las normas de bioseguridad como el uso de mascarillas y el distanciamiento social. En Perú el número de casos a la fecha es de 2.243.415, fallecidos 201.379 , letalidad $8,98 \%$ y la cobertura de vacunaciones con dos dosis ha alcanzado $59.11 \% \% 2$.

Hasta antes de la COVID-19 se consideraba a la obesidad como la pandemia del siglo XXI, ahora con el advenimiento de esta última, se han asociado causando mayores daños. La obesidad se ha establecido como factor de riesgo para hospitalización, ingreso a UCI, uso de ventilación mecánica y mortalidad por el Covid-193. Entre los mecanismos de acción de la obesidad se señalan incremento en la expresión de la enzima convertidora de angiotensina 2 (ACE2), el cual puede unirse a la proteína spike (SP) del SARS-Cov-2 haciendo al tejido adiposo un portal para la invasión viral, con mayor vulnerabilidad de los pulmones y corazón al ataque del virus; también aumento del estado inflamatorio de respuesta inmune, la cual puede agravar la infección y COVID-19; finalmente incremento de la presión abdominal, limitada expansión del tórax y función compensatoria respiratoria insuficiente ${ }^{3}$.

La pandemia de la COVID-19 por su parte ha aumentado la frecuencia de sobrepeso y obesidad por la disminución de la actividad física por la cuarentena y el aislamiento, y en algunas realidades con la modificación de los hábitos alimenticios, como lo señala Robinson en el Reino Unido en un estudio de 2000 adultos 4 .

En el Perú la frecuencia de obesidad ha aumentado en el 2020 según referencia del INEI alcanzando el 24,6\% de la población de 15 y más años de edad, registrándose un aumento de 3,6 puntos porcentuales al compararlo con el año 20175. En los estudiantes de medicina se ha señalado que el $50 \%$ tienen sobrepeso $\mathrm{u}$ obesidad6. Ello implica un problema de salud porque se asocia a hipertensión, síndrome metabólico y mayor riesgo cardiovascular y de diabetes. Se requiere un programa nacional de prevención fomentando en la población el ejercicio, dieta saludable con mayor ingesta de frutas, verduras, pescado y menor consumo de comida hipercalóricas, grasas saturadas y azúcar refinado. Asimismo incluir la nutrición en los programas de estudios de las carreras de la salud y realizar investigaciones sobre esta realidad en niños, adultos $\mathrm{y}$ adultos mayores 


\section{Referencias bibliográficas}

1. John Hopkins.Coronavirus Resource Center https://coronavirus.jhu.edu/map.html 9.de diciembre 2021

2. MINSA.Sala Situacional Covid-19 Peru. https://covid19.minsa.gob.pe/sala_situacional.asp

3. Yan J, Hu J, Zhu Ch. Obesity aggravates COVID-19: A systematic review and meta-analysis $\mathrm{J}$ Med Virology 2020(june)Disponible https://onlinelibrary.wiley.com/doi/full/10.1002/jmv.26237. https://doi.org/10.1002/jmv.26237
4. Robinson E, Boyland E, Chisholm A, Harrold J, Maloney N, Marty $L$ et al . Obesity, eating behavior and physical activity during COVID-19 lockdown: A study of UK adults. Appetite 2021 Jan 1;156:104853. doi: 10.1016/j.appet.2020.104853. Epub 2020 Oct 7

5. INEI. Notas de prensa https://www.inei.gob.pe/prensa/noticias/el-399-de-peruanos-de15-y-mas-anos-de-edad-tiene-al-menos-una-comorbilidad$12903 /$

6. Muñoz-BlancoP,Huamán-Saavedra J.Estado nutricional de estudiantes de Medicina de la Universidad Nacional de Trujillo.Rev méd Trujillo 2018;13(3):131-9 